\title{
Clinical and Laboratory Diagnosis of Inherited Platelet Function Disorders
}

\author{
Peter Bugert \\ Institute of Transfusion Medicine and Immunology, Heidelberg University, Medical Faculty Mannheim, \\ German Red Cross Blood Service of Baden-Württemberg - Hessen gGmbH, Mannheim, Germany
}

In the present issue of Transfusion Medicine And HemotherAPY current strategies for the diagnosis of inherited platelet function disorders that have been established in different clinics in the German-speaking countries are summarized. These strategies are partially related to diagnostic algorithms applied in Italy or the UK $[1,2]$. Inherited platelet function disorders represent a heterogeneous group of hemostaseologic diseases with predominantly mild to moderate bleeding symptoms. Very often a platelet function defect is not recognized in the newborn due to the mild symptoms. However, in the adolescent age bleeding complications such as menorrhagia or prolonged bleeding after injuries or tooth extraction may occur. Thus the correct incidence, especially of platelet function disorders with mild bleeding, is still unclear. The development and application of diagnostic algorithms is an important prerequisite to improve the identification and subsequent treatment of inherited platelet disorders.

Strategies for the differential clinical and laboratory diagnosis of inherited platelet function disorders have been developed at different specialized centers and are presented in this issue [3-6]. The significant expertise of these centers should be integrated into national guidelines for the diagnosis and treatment of patients with inherited or acquired platelet function disorders that still do not exist for German-speaking countries. The implementation of a standardized questionnaire to assess bleeding symptoms, bleeding history, family history with regard to bleeding, and medication is regarded as one of the most important diagnostic modules [3, 4]. Such questionnaires could be easily used even at non-specialized facilities and should be part of a differential diagnosis of inherited/acquired platelet/coagulation disorders. The systematic assessment of bleeding data could also help to make decisions with regard to further laboratory diagnosis.

A broad spectrum of methods and techniques is currently used in the laboratory diagnosis of platelet function disorders.
With regard to equipment, the techniques could be rather simple such as blood smears evaluated by light microscopy or more laborious such as molecular genetic investigation of target genes by DNA sequencing. In addition, depending on the method the levels of standardization are quite different and could necessitate substantial degree of experience. Other methods such as platelet aggregation are widely in use but are still challenging with regard to standardization and comparability between laboratories due to different devices and reagents. However, more recently developed devices (e.g. VerifyNow $^{\circledR}$ or Multiplate ${ }^{\circledR}$ ) could be implemented as pointof-care tests (POCT), probably with the potential for standardization. Based on rather simple and standardized tests, a first-line laboratory diagnosis of platelet function disorders could be established even at non-specialized facilities. Confirmatory testing and further differential diagnosis is then performed at specialized centers.

The portfolio of laboratories specialized on the diagnosis of platelet function disorders usually includes further techniques and methods in addition to standard tests (blood count, blood smear, aggregometry). This could include quantification of platelet glycoproteins by flow cytometry and Western blotting, evaluation of the platelet ultrastructure by electron microscopy, measurement of granule secretion by ELISA or luminometry, and the identification of inclusion bodies by blood smear immunofluorescence microscopy [4-6]. The specialized laboratories also perform molecular genetic testing in order to elucidate the molecular basis of a platelet defect. As soon as the causal mutation has been identified, further testing of the patients' families is much easier. The characterization of gene mutations is also an important contribution to describe genotype-phenotype correlations and to a better understanding of the pathomechanisms of the disorders [7, 8].

Very often blood samples of patients with suspected platelet function disorder are sent to specialized laboratories for

\section{KARGER}

Fax +49 761452071

Information@Karger.de

www.karger.com (c) 2010 S. Karger GmbH, Freiburg

Accessible online at:

www.karger.com/tmh 
diagnostic investigations. However, many platelet function tests, especially aggregation assays, require fresh blood samples and should be performed within a few hours after blood withdrawal. This problem may be solved by the use of anticoagulants that show a better preservation of platelet function, e.g. the synthetic thrombin and factor Xa inhibitor benzylsulfonyl-D-Arg-Pro-4-amidinobenzylamide (BAPA). Furthermore, blood sample tubes with dried lepirudin may be beneficial compared to liquid lepirudin with regard to handling. The validation of such anticoagulants in platelet aggregation testing is an important step towards their use in the clinic and laboratory $[9,10]$. Further validation studies are also needed to prove the benefits proposed for the POCT platelet aggregation devices. This could include the investigation of poten- tial antiplatelet effects of therapeutic drugs taken by the patients [11].

The standardized laboratory diagnosis of platelet function disorders is under continuous progression with the avenue to further improvement. This process could include the further standardization and validation of established assays (blood cell counting, blood smear, platelet aggregation, flow cytometry, Western blotting, etc.) as well as the development of new tools to further assess platelet function $[12,13]$. Due to economic reasons many of the platelet function tests will be performed only in specialized laboratories. However, a preliminary first-line diagnosis of a platelet function disorder at nonspecialized facilities could be enabled by the introduction of simple and standardized tests.

\section{References}

$>1$ Balduini CL, Cattaneo M, Fabris F, Gresele P, Iolascon A, Pulcinelli FM, Savoia A: Inherited thrombocytopeias: a proposed diagnostic algorithm from the Italian Gruppo di Studio delle Piastrine. Haematologica 2003;88:582-592.

2 Bolton-Maggs PHB, Chalmers EA, Collins PW, Harrison P, Kitchen S, Liesner RJ, Minford A, Mumford AD, Parapia LA, Perry DJ, Watson SP, Wilde JT, Williams MD: A review of inherited platelet disorders with guidelines for their management on behalf of the UKHCDO. Br J Haematol 2006;135:603-633.

3 Knöfler R, Streif W: Strategies in clinical and laboratory diagnosis of inherited platelet function disorders in children. Transfus Med Hemother 2010; 37(5):231-235.

4 Kirchmaier CM, Pillitteri D: Diagnosis and management of inherited platelet disorders. Transfus Med Hemother 2010;37(5):237-246.
5 Sandrock K, Zieger B: Current strategies in diagnosis of inherited storage pool defects. Transfus Med Hemother 2010;37(5):248-258.

6 Althaus K, Greinacher A: MYH-9 related platelet disorders: strategies for management and diagnosis. Transfus Med Hemother 2010;37(5):260-267.

7 Pillitteri D, Pilgrimm AK, Kirchmaier CM: Novel mutations in the GPIIb and GPIIIa genes in Glanzmann thrombastenia. Transfus Med Hemother 2010;37(5):268-277.

8 Sandrock K, Knöfler R, Greinacher A, Fürll B, Gerisch S, Schuler U, Gehrisch S, Busse A, Zieger B: A novel mutation in Bernard-Soulier syndrome. Transfus Med Hemother 2010;37(5):278-283.

$\checkmark 9$ Tauer JT, Lohse J, König S, Knöfler R: Investigations of platelet function in whole blood with BAPA as anticoagulant. Transfus Med Hemother 2010;37(5):284-288.
10 Loreth RM, Klose G: Comparison of two different blood sample tubes for platelet function analysis with the Multiplate ${ }^{\circledast}$ system. Transfus Med Hemother 2010;37(5):289-292.

11 Schedel A, Thornton S, Klüter H, Bugert P: The effect of psychoactive drugs on in vitro platelet function. Transfus Med Hemother 2010;37(5):293298.

12 Hermann M, Nussbaumer O, Knöfler R, Hengster P, Nussbaumer W, Streif W: Real-time live confocal fluorscence microscopy as a new tool for assessing platelet vitality. Transfus Med Hemother 2010; 37(5):299-305.

13 Kraus M-J, Strasser EF, Eckstein R: A new method for measuring the dynamic shape change of platelets. Transfus Med Hemother 2010;37(5):306-310. 